\title{
In vitro Antidiabetic Activities of Two Sorbus Species
}

\author{
Gozde Hasbal, Tugba Yilmaz Ozden*, Ayse Can \\ Istanbul University, Faculty of Pharmacy, Department of Biochemistry, Istanbul, Turkey
}

Please cite this article as: Hasbal G, Yilmaz Ozden T, Can A. In vitro Antidiabetic Activities of Two Sorbus Species. Eur J Biol 2017; 76(2): 57-60.

\begin{abstract}
Fruits of several Sorbus species (Rosaceace) are used both in traditional medicine as antidiabetic, antiinflammatory, diuretic, vasoprotective and in foods. In this study, in vitro antidiabetic activities of water extracts of Sorbus aucuparia L. (rowan tree) and Sorbus torminalis L. Crantz (wild sevice tree) fruits were investigated by measuring inhibitory potentials on a-glucosidase and pancreatic a-amylase activities, the most important digestive enzymes. Also, the total phenolic and flavonoid contents of the fruits were determined to evaluate the association between phenolic content and antidiabetic activity. S. torminalis and S. aucuparia extracts exhibited strong a-glucosidase inhibitory activity, more effective than that of standard drug acarbose. However, S. torminalis has shown moderate inhibitory effect against a-amylase while S. aucuparia exhibited weak inhibition. The total phenolic and flavonoid contents of the fruits were correlated with andiabetic activities. It has been suggested that antidiabetic effects of the fruits may be due to phenolic compounds present therein. Therefore, S. aucuparia and S. torminalis fruits might be potential sources of antidiabetic compounds.
\end{abstract}

Keywords: Sorbus aucuparia, Sorbus torminalis, antidiabetic activity, a-amylase, a-glucosidase.

\section{INTRODUCTION}

Diabetes mellitus is a group of metabolic diseases (1). Type 2 diabetes mellitus contains $\beta$-cell dysfunction and insulin resistance. When the $\beta$-cell function decreases over time, fasting blood glucose and postprandial glucose levels begin to rise and remain out of control (2). In the world wide, prevalence of type 2 diabetes is increasing due to lifestyle-related risk factors such as smoking, obesity, poor diabetes and physical inactivity (1). The increased prevalence of type 2 diabetes has led to the development of many new approaches in the treatment of hyperglycemia. The purpose of these treatments is to reduce and maintain glucose concentrations as normal as possible and thus prevent development of complications (3). Sample treatments include a-glucosidase inhibitors (AGls; acarbose, miglitol and voglibose) to reduce the absorption of carbohydrates in the intestine and control postprandial hyperglycemia. Acarbose inhibits both a-amylase (EC 3.2.1.1) and a-glucosidases (EC 3.2.1.20), thus preventing absorption of starch and other carbohydrates from the intestine also reduces postprandial glycaemia and helps manage diabetes (4). Lately, there has been much interest in the investigations of the natural a-glucosidase inhibitors for diabetes treatment (5).

Nature is a good source of antidiabetic drugs and plants are valuable dietary supplements to improve blood sugar control and prevent long-term complications of type 2 diabetes (2). Polyphenols are naturally occurring compounds found largely in the fruits (especially like grapes, apples, cherries and berries) and vegetables. Several studies revealed that long-time intake of plant polyphenols in diets have a protective effect to development of many diseases such as diabetes (6).

The genus Sorbus mostly distributed in Northern Hemisphere, comprises about 250 species of trees and shrubs. Fruits of several Sorbus species (berries) included S. domestica, S. aucuparia and S. torminalis from family Rosaceace are consumed as food sources and used as traditional medicine (7). Also, Sorbus species are called 'uvez' in Turkish, which have been used as traditional medicinal 
plants for various purposes in Turkish folk medicine (8). S. domestica fruits are consumed by the local population in Greece, not only as a nutritious food, but also traditionally as an antidiabetic agent (9). In this study, we investigated in vitro inhibitory effects of two Sorbus species on a-glucosidase and a-amylase activities. The antidiabetic activities and amount of total phenolics of S. aucuparia and S. torminalis fruits has been determined, comparatively. Although there are limited number of studies on S. aucuparia fruits, there is no study showing the antidiabetic effects of S. torminalis.

\section{MATERIAL AND METHODS}

\section{Chemicals and Reagents}

a-Amylase, a-glucosidase, acarbose, 3,5-dinitrosalicylic acid (DNS), Folin-Ciocalteu reagent, gallic acid, p-nitrophenyl a-D-glucopyranoside (PNPG) and starch purchased from Sigma Chemical Co. (St. Louis, MO, USA). Catechin was purchased from Fluka Chemical Co. (Buchs, Switzerland). All other chemicals or reagents were of analytical grade.

\section{Preparation of Extracts}

The fruits of S. aucuparia and S.torminalis were obtained from Black Sea Region and Istanbul, respectively. Decoctions are one of the most consumed drinkable forms of plants (10). For this reason, the fruit extracts were obtained by using decoction method. After the seeds were removed, fruits were dried in the shade. To prepare the water extracts, $15 \mathrm{~g}$ of the fruits were refluxed with distilled water for 3 hours. The extracts were filtered and the solvent was evaporated (Buchi, Switzerland) to dryness under reduced pressure. The fruits extracts were stored in $-20^{\circ} \mathrm{C}$ until needed. For the biochemical assays, the extracts were dissolved in distilled water.

\section{Determination of a-Glucosidase Inhibitory Activity}

The a-glucosidase inhibitory effects of the fruit extracts were evaluated using a procedure described by Bothon et al. (11). For the a-glucosidase assay, $25 \mu \mathrm{L}$ of the fruit extract was mixed with $75 \mu \mathrm{L}$ of $0.1 \mathrm{M}$ sodium phosphate buffer $(\mathrm{pH} 6.8)$ and $50 \mu \mathrm{L}$ of a-glucosidase solution $(1 \mathrm{U} / \mathrm{mL})$ and preincubated at $37^{\circ} \mathrm{C}$ for 10 minutes. After incubation, $50 \mu \mathrm{L}$ of substrate solution $(5 \mathrm{mM}$ PNPG) was added to the reaction mixture and the absorbance change at $405 \mathrm{~nm}$ was measured at $37^{\circ} \mathrm{C}$ for 10 minutes using a microplate reader. Acarbose was used as a standard and replacing the extract with distilled water was used a control. The inhibitory activities of the extracts were identified according to the following formula:

$\%$ Inhibition $=\left(1-\frac{\text { Reaction rate of sample at } 405 \mathrm{~nm}}{\text { Reaction rate of control at } 405 \mathrm{~nm}}\right) \times 100$

\section{Determination of a-Amylase Inhibitory Activity}

The inhibition of a-amylase by the Sorbus fruits was determined using the DNS method (12). Briefly, $10 \mu \mathrm{L}$ of each extract were preincubated with $50 \mu \mathrm{L}$ of a-amylase solution $(3 \mathrm{U} / \mathrm{mL})$ and 40 $\mu \mathrm{L}$ of $0.1 \mathrm{M}$ sodium phosphate buffer $(\mathrm{pH} 6.8)$ at $25^{\circ} \mathrm{C}$ for $10 \mathrm{~min}-$ utes. The reaction was initiated by adding $50 \mu \mathrm{L}$ starch solution $(0.75 \%)$. After 5 minutes, the reaction was stopped by adding $75 \mu \mathrm{L}$ of DNS color reagent (96 mM DNS and 5.31 M potassi- um sodium tartarate in $2 \mathrm{M} \mathrm{NaOH})$. The mixtures were heated at $85^{\circ} \mathrm{C}$ for 15 minutes. After cooling, the mixture was diluted 4-fold with distilled water and absorbance was recorded at 540 $\mathrm{nm}$. Acarbose was used as a standard and control was prepared without inhibitor. The inhibitory activities of the extracts were identified according to the following formula:

$\%$ Inhibition $=\left(1-\frac{\text { Absorbance of sample at } 540 \mathrm{~nm}}{\text { Absorbance of control at } 540 \mathrm{~nm}}\right) \times 100$

Determination of Total Phenolic and Flavonoid Compounds Total phenolic and flavonoid contents of the extracts were determined using the Folin-Ciocalteu (13) and the aluminum chloride (14) methods, respectively. For the determination of total phenolics, $5 \mu \mathrm{L}$ of fruit extract was mixed with $225 \mu \mathrm{L}$ of distilled water, $5 \mu \mathrm{L}$ of $2 \mathrm{~N}$ Folin-Ciocalteu reagent (previously diluted with distilled water $1: 2 ; \mathrm{v}: \mathrm{v}$ ) and $15 \mu \mathrm{L}$ of $2 \% \mathrm{Na}_{2} \mathrm{CO}_{3}$ solution. The mixture was incubated in dark for 2 hours at room temperature. After incubation, absorbance was measured at $760 \mathrm{~nm}$. Total phenolic contents were determined using equation of standard regression curve which obtained by gallic acid solution and were expressed in $\mathrm{mg}$ of gallic acid equivalents (GAE).g extract ${ }^{-1}$.

For the determination total flavonoids, $25 \mu \mathrm{L}$ of fruit extract was mixed $125 \mu \mathrm{L}$ of distilled water and $7.5 \mu \mathrm{L}$ of $5 \% \mathrm{NaNO}_{2}$ solution then incubated for 6 minutes. Then, $15 \mu \mathrm{L}$ of $10 \% \mathrm{AlCl}_{3}$ solution was added. After 5 minutes incubation at room temperature, $50 \mu \mathrm{L}$ of $1 \mathrm{M} \mathrm{NaOH}$ solution and $27.5 \mu \mathrm{L}$ of distilled water was added. The absorbance was recorded at $510 \mathrm{~nm}$. Total flavonoid contents were determined using equation of standard regression curve which obtained by catechin solution and were expressed in $\mathrm{mg}$ of catechin equivalents (CE).g extract ${ }^{-1}$.

\section{Statistical Analysis}

The results were evaluated using unpaired t-test with NCSS statistical computer package (NCSS, Kaysville, UT, USA) and the differences were considered significant at $\mathrm{p}<0.05$.

\section{RESULTS}

In this study, the inhibitory effects of two Sorbus species and acarbose on a-glucosidase and a-amylase activities were investigated. It was found that S. torminalis and S. aucuparia showed strong and dose dependent inhibitory activities against a-glucosidase (Figure 1). The half-maximal inhibitory concentration $\left(\mathrm{IC}_{50}\right)$ values of the Sorbus extracts and acarbose are presented in Table 1. Comparison of the $\mathrm{IC}_{50}$ values revealed that the inhibitory effects of both $S$. torminalis and $S$. aucuparia extracts on a-glucosidase were approximately four and two fold higher than that of acarbose, respectively. As shown in Figure 2, S. torminalis exhibited $75.32 \pm 2.80 \%$ a-amylase inhibitory activity at $0.8 \mathrm{mg} \cdot \mathrm{mL}^{-1}$ concentration while $S$. aucuparia exhibited only $22.08 \pm 1.17 \%$ inhibition at same concentration.

Also, the total phenolic and flavonoid contents of the extracts are shown in Table 2. The results showed that $S$. torminalis water extract had the highest total phenolic and total flavonoid contents. These results demonstrate that there was a high correlation between the antidiabetic activity and the phenolic contents. 

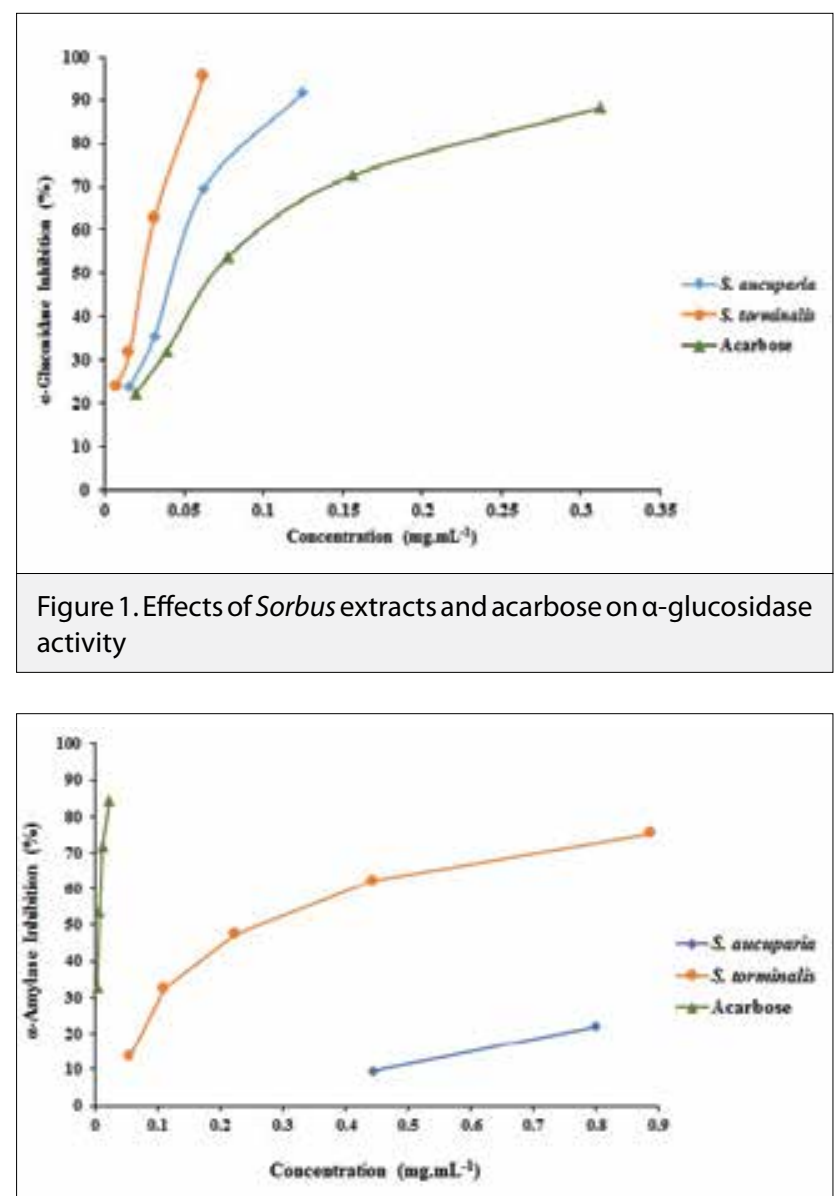

Figure 2. Effects of Sorbus extracts and acarbose on a-amylase activity

\section{DISCUSSION}

One of the therapeutic approaches in the treatment of diabetes mellitus is reduction of postprandial hyperglycemia (15). The rate of starch digestion is the most important factor affecting of blood glucose level. Since a-glucosidase and a-amylase have a crucial function in carbohydrate hydrolysis, inhibition of these enzymes is one of the most therapeutic strategy for the treatment of diabetes (5). In this study, we evaluated a-glucosidase and a-amylase inhibitory activities of two Sorbus species. Our results showed that $S$. torminalis and S. aucuparia strongly inhibited a-glucosidase activity indicates tested species have antidiabetic effects. However, S. torminalis and S. aucuparia showed moderate and weak inhibitory effect on a-amylase, respectively. In literature, there have been limited studies on the antidiabetic effects of $S$. aucuparia fruits while no studies showing antidiabetic activity of the $S$. torminalis fruit were found. In these studies, the antidiabetic effect of $S$. aucuparia fruit extract was reported by measuring a-amylase inhibitory activity (16) and a-glucosidase inhibitory activity (1). These results are consistent with the data obtained from this study. Also, antidiabetic potentials of different Sorbus species (S. decora and S. tianschanica) have been reported in diabetic animal models $(17,18)$.
Table 1. a-Glucosidase and a-amylase inhibitory activities of the extracts and acarbose

\begin{tabular}{lcc}
\hline & \multicolumn{2}{c}{ Inhibitory activity $\left(\right.$ IC $_{\mathbf{5 0}} \mathbf{~ m g . \mathbf { m L } ^ { - 1 } )}$} \\
\cline { 2 - 3 } & a-amylase & a-glucosidase \\
\hline S. aucuparia & ND & $0.050 \pm 0.0005^{\mathrm{a}}$ \\
\hline S. torminalis & $0.307 \pm 0.0158^{\mathrm{a}}$ & $0.027 \pm 0.0006^{\mathrm{b}}$ \\
\hline Acarbose & $0.006 \pm 0.0002^{\mathrm{b}}$ & $0.086 \pm 0.0027^{\mathrm{c}}$ \\
\hline
\end{tabular}

Data are presented as the mean of three replicates \pm standard deviation. Different superscript letters in the same column indicate a significant difference $(p<0.05)$. IC50; The inhibitory concentration of the extract or acarbose required to inhibit the activity of the enzyme by $50 \%$. IC50 values were calculated from dose-response curves using Microsoft Excel. All concentrations are the final extract concentrations in the reaction mixture. ND; Not determined.

Table 2. Total phenolics contents (TPC) and total flavonoid contents (TFC) of the extracts

\begin{tabular}{|c|c|c|}
\hline & TPC (GAE.g extract ${ }^{-1}$ ) & TFC (CE.g extract $\left.{ }^{-1}\right)$ \\
\hline S. aucuparia & $19.13 \pm 0.76$ & $9.62 \pm 0.27$ \\
\hline S. torminalis & 24.210 .61 & $15.69 \pm 0.55$ \\
\hline \multicolumn{3}{|c|}{$\begin{array}{l}\text { Data are presented as the mean of three replicates } \pm \text { standard deviation. } \\
\text { GAE.g extract }{ }^{-1} ; \mathrm{mg} \text { gallic acid equivalents.g extract }{ }^{-1} \text {. } \\
\text { CE.g extract }{ }^{-1} ; \mathrm{mg} \text { catechin equivalents.g extract }{ }^{-1} \text {. }\end{array}$} \\
\hline
\end{tabular}

In this study, we also determined the total phenolic and flavonoid contents of the fruit extracts. It was found that there was a high correlation between phenolic contents and in vitro antidiabetic acitivity. Antidiabetic effects of polyphenolic compounds have been shown in numerous studies $(6,19)$. It has been suggested that hypoglycemic effects of fruits and vegetables may stem from the insulin-like or insulin releasing activities of phenolic compounds present therein (2). Also, a-glucosidase and a-amylase inhibitory potentials of various plant polyphenols such as catechins, diacetylated anthocyanins and alkaloids have been reported in several studies $(2,6,20)$. Phenolic composition of S. torminalis and S. aucuparia fruits have been shown in previous studies $(21,22)$. Based on the correlation between the results of the assays, we can say that the phenolic compounds in the fruit extracts are responsible for its antidiabetic activity.

In recent work, we demonstrated that the extracts from Sorbus fruits especially $S$. torminalis, potently inhibit a-glucosidase and a-amylase in vitro. It is reasonable to hypothesize that consumption of Sorbus fruits may reduce intestinal absorption of sugars via inhibition of these digestive enzymes. Also, these fruits can be a potential source of natural antidiabetic agents. These findings may scientifically explain some uses of this species in folk medicine as an antidiabetic agent.

\section{Acknowledgement}

Gozde Hasbal thanks to The Scientific and Technological Research Council of Turkey (TUBITAK) for National PhD Scholarship Programme (BIDEB 2211-C). 


\section{REFERENCES}

1. Boath AS, Stewart D, McDougall GJ. Berry components inhibit a-glucosidase in vitro: Synergies between acarbose and polyphenols from black currant and rowanberry. Food Chem 2012; 135(3): 929-36. [CrossRef]

2. Beidokhti MN, Jäger AK. Review of antidiabetic fruits, vegetables, beverages, oils and spices commonly consumed in the diet. J Ethnopharmacol 2017; 201: 26-41. [CrossRef]

3. Kahn SE, Cooper ME, Del Prato S. Pathophysiology and treatment of type 2 diabetes: Perspectives on the past, present, and future. Lancet 2014; 383(9922): 1068-83. [CrossRef]

4. Kalra S. Alpha glucosidase inhibitors. J Pak Med Assoc 2014; 64(4): 474-6.

5. Dehghan H, Sarrafi Y, Salehi P. Antioxidant and antidiabetic activities of 11 herbal plants from Hyrcania region, Iran. J Food Drug Anal 2016; 24(1): 179-88. [CrossRef]

6. Pandey KB, Rizvi SI. Plant polyphenols as dietary antioxidants in human health and disease. Oxid Med Cell Longev 2009; 2(5): 2708. [CrossRef]

7. Olszewska M. Separation of quercetin, sexangularetin, kaempferol and isorhamnetin for simultaneous HPLC determination of flavonoid aglycones in inflorescences, leaves and fruits of three Sorbus species. J Pharmaceut Biomed 2008; 48(3): 629-35. [CrossRef]

8. Baytop T. Therapy with Medicinal Plants in Turkey (Past and Present). Istanbul: Nobel Tip Kitabevleri Press; 1999.

9. Termentzi A, Kefalas P, Kokkalou E. LC-DAD-MS (ESI+) analysis of the phenolic content of Sorbus domestica fruits in relation to their maturity stage. Food Chem 2008; 106(3): 1234-45. [CrossRef]

10. Fotakis C, Tsigrimani D, Tsiaka T, Lantzouraki DZ, Strati IF, Makris C, et al. Metabolic and antioxidant profiles of herbal infusions and decoctions. Food Chem 2016; 211: 963-71. [CrossRef]

11. Bothon FT, Debiton E, Avlessi F, Forestier C, Teulade JC, Sohounhloue DK. In vitro biological effects of two anti-diabetic medicinal plants used in Benin as folk medicine. BMC Complem Altern M 2013; 13(1): 51 (open access). [CrossRef]
12. Ali $\mathrm{H}$, Houghton PJ, Soumyanath A. a-Amylase inhibitory activity of some Malaysian plants used to treat diabetes; with particular reference to Phyllanthus amarus. J Ethnopharmacol 2006; 107(3): 449-55. [CrossRef]

13. Slinkard K, Singleton VL. Total phenol analysis: automation and comparison with manual methods. Am J Enol Viticult 1977; 28(1): 49-55.

14. Kim DO, Chun OK, Kim YJ, Moon HY, Lee CY. Quantification of polyphenolics and their antioxidant capacity in fresh plums. J Agr Food Chem 2003; 51(22): 6509-15. [CrossRef]

15. Ogbole OO, Aliu LO, Abiodun OO, Ajaiyeoba EO. Alpha-amylase inhibition and brine shrimp lethality activities of nine medicinal plant extracts from South-West Nigerian ethnomedicine. J Herbs Spices Med Plants 2016; 22(4): 319-26. [CrossRef]

16. Grussu D, Stewart D, McDougall GJ. Berry polyphenols inhibit a-amylase in vitro: identifying active components in rowanberry and raspberry. J Agr Food Chem 2011; 59(6): 2324-31. [CrossRef]

17. Vianna R, Brault A, Martineau LC, Couture R, Arnason JT, Haddad PS. In vivo anti-diabetic activity of the ethanolic crude extract of Sorbus decora CK Schneid. (Rosacea): A medicinal plant used by Canadian James Bay Cree nations to treat symptoms related to diabetes. Evid Based Complement Alternat Med 2011; 2011: 237941. [CrossRef]

18. Li L, Su X, Tang H. Hypoglycemic effects of the n-butanol part of Sorbus tianschanica. Medicinal Plant 2014; 5(5): 1-2.

19. Tiwari AK, Rao JM. Diabetes mellitus and multiple therapeutic approaches of phytochemicals: Present status and future prospects. Curr Sci 2002; 83(1): 30-8.

20. Dembinska-Kiec A, Mykkänen O, Kiec-Wilk B, Mykkänen H. Antioxidant phytochemicals against type 2 diabetes. Br J Nutr 2008; 99(E-S1), ES109-ES117.

21. Olszewska MA, Michel P. Antioxidant activity of inflorescences, leaves and fruits of three Sorbus species in relation to their polyphenolic composition. Nat Prod Res 2009; 23(16): 1507-21. [CrossRef]

22. Mrkonjić ZO, Nađpal J, Beara I, Sabo VA, Četojević-Simin D, Mimica-Dukić $\mathrm{N}$, et al. Phenolic profiling and bioactivities of fresh fruits and jam of Sorbus species. J Serb Chem Soc 2017; 82(6): 651-64. [CrossRef] 